\title{
GESTÃO DA INOVAÇÃO: O CASO DE UMA INSTITUIÇÃO FINANCEIRA BRASILEIRA
}

INNOVATION MANAGEMENT: THE CASE OF A BRAZILIAN FINANCIAL INSTITUTION

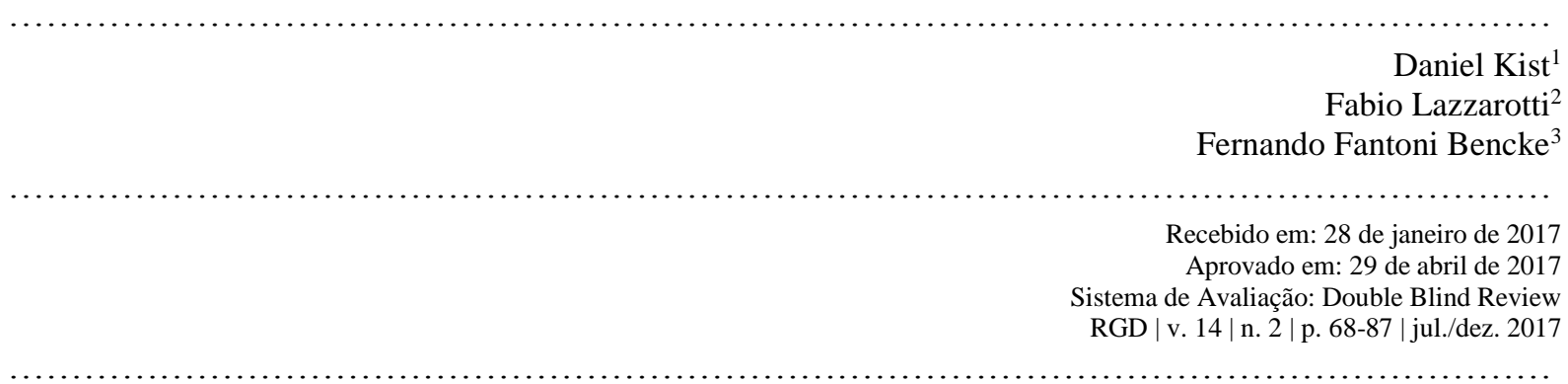

\section{RESUMO}

O objetivo do estudo consistiu em analisar o processo de gestão da inovação, a partir do paradigma da inovação aberta, em uma instituição financeira brasileira. $O$ estudo sobre a inovação aberta em instituições financeiras e, nesse particular, no setor bancário brasileiro, ainda é incipiente e carece de evidências empíricas que tratam da sua relevância em um ambiente dinâmico e competitivo. A pesquisa foi desenvolvida por meio da abordagem qualitativa, do tipo exploratório e descritivo, com aplicação de entrevistas semiestruturadas. Utilizou-se análise de documentos e observações em visita técnica guiada. Para análise dos dados foi utilizada a técnica de análise de conteúdo a partir de categorias definidas $a$ priori consubstanciadas na literatura pesquisada: modelo de gestão da inovação; fontes de obtenção de inovações (internas e externas); e ambiente organizacional voltado à inovação aberta. Os resultados obtidos evidenciaram que a instituição financeira detém muitos aspectos de inovação fechada, relacionados principalmente à estrutura e cultura organizacional. Da mesma forma, evidenciou-se pouco uso de mecanismos de inovação aberta, com a exploração de poucas fontes de relacionamento externo para a promoção da inovação. Pode-se concluir com o estudo, que a organização está em um estágio intermediário, que integra ora características da inovação fechada e ora da inovação aberta.

Palavras-chave: Gestão da Inovação. Inovação aberta. Instituições financeiras.

\begin{abstract}
The study aims to analyze the process of innovation management, based on the paradigm of open innovation, in a Brazilian financial institution. The study on open innovation in financial institutions and, in particular, in the Brazilian banking sector, is still incipient and lacks empirical evidence that deals with its relevance in a dynamic and competitive environment. The research was developed through the qualitative approach, of the exploratory and descriptive, with the application of semistructured interviews. We used document analysis and observations in a guided technical visit. To analyze the data, the content analysis technique was used based on categories defined a priori embodied in the researched literature: innovation management model; Sources of innovation (internal and external); And an organizational environment focused on open innovation. The results obtained evidenced that the financial institution has many aspects of closed innovation, related mainly to organizational structure and culture. Likewise, there was evidence the little use of open innovation mechanisms, with the exploitation of few sources of external relations for the promotion of innovation. It can be concluded from the study that the organization is in an intermediate stage, which integrates both characteristics of closed innovation and now open innovation.
\end{abstract}

Keywords: Innovation Management. Open innovation. Financial Institution.

\footnotetext{
${ }^{1}$ Mestre em Administração (Universidade do Oeste de Santa Catarina/Brasil). E-mail: danielkist.dk@ gmail.com.

2 Doutor em Administração e Turismo (Universidade do Vale do Itajaí/Brasil). Professor na Universidade do Oeste de Santa Catarina (Joaçaba/Brasil). E-mail: fabio.lazzarotti@unoesc.edu.br.

${ }^{3}$ Doutor em Administração (Universidade de Caxias do Sul/Brasil). E-mail: fernando.bencke@unoesc.edu.br.
} 


\section{INTRODUÇÃO}

Entende-se que a inovação é um fator fundamental para sobrevivência e competitividade das organizações, um tema muito discutido atualmente na academia e nas organizações. A inovação é considerada um dos principais motores do crescimento econômico de longo prazo, e uma estrutura organizacional adequada pode impulsionar o progresso sustentável de uma instituição financeira (FASNACHT, 2009).

A velocidade com que as mudanças acontecem atualmente, e com que as inovações são difundidas, exige das empresas uma eficiente gestão das inovações e de forma consistente para garantirem sua posição no mercado competitivo. Neste cenário, as organizações podem ser capazes de reunir recursos e competências de forma a facilitar o acesso a novas informações e tecnologias (TIGRE, 2006).

O modelo de inovação aberta de Chesbrough (2012a) surge como alternativa ao modelo tradicional de gestão, diminuindo as fronteiras das organizações e permitindo um fluxo intenso de informações: de fora para dentro, aproveitando informações externas para acelerar as inovações; e de dentro para fora, levando as ideias ao mercado, a fim de gerar valor adicional.

No presente trabalho, pretendeu-se analisar o processo de gestão da inovação em uma instituição financeira brasileira pelo paradigma da inovação aberta. O tema inovação aberta ainda é uma incógnita nesse setor, que passa por mudanças significativas nos últimos anos, principalmente após a última crise financeira mundial (2008-2009). A competitividade acirrada do setor, a ameaça de novos entrantes no mercado, representado por empresas de tecnologia como, por exemplo, o Google e a Paypal, com formas de atuação mais próximas dos anseios de seus clientes, com baixo nível de burocracia e agilidade de adaptação às mudanças globais (FASNACHT, 2009), exige um repensar das instituições financeiras sobre os modelos de gestão da inovação adotados.

A relevância da realização deste estudo se deve, basicamente, a três fatores. Primeiro, a importância do setor bancário no crescimento e desenvolvimento do País, contribuindo de forma significativa para a competitividade das empresas e financiamento às pessoas físicas, representando 55,9\% do PIB (BANCO CENTRAL DO BRASIL, 2014). O sistema financeiro contribui positivamente para o crescimento econômico, conforme se constata em pesquisa elaborada por Silva e Porto Junior (2006), sendo um bom sinalizador para um bom desempenho da economia. "Neste sentido, a intuição de Schumpeter acerca do sistema financeiro parece ser apropriada, pois há evidências de uma relação estreita entre inovação e desenvolvimento financeiro" (SILVA; PORTO JUNIOR, 2006, p. 440). Segundo, é importante observar que existe uma "conexão estabelecida [...] entre o crédito e a realização de inovações" e ainda que "o crédito é primariamente necessário às novas combinações [...] e na realização de combinações novas, o "financiamento", como um ato especial, é fundamentalmente necessário, na prática como na teoria" (SCHUMPETER, 1934, p. 79-80). E terceiro, há constatação de poucos estudos abordando esta temática no contexto de instituições financeiras brasileiras.

A inovação no sistema bancário brasileiro apresenta resistência em alguns aspectos. Os bancos reconhecem a importância da interação e troca de informações com os clientes, mas é pouco provável que exista uma abertura efetiva, de dentro para fora dessas organizações (PIRES; MARCONDES, 2004). Segundo Pires e Marcondes (2004, p. 73), "a ênfase está sendo dada à manipulação das bases de dados sobre os clientes de modo a se manter e lançar novos produtos, mas não como oportunidade de aprendizado com o conhecimento acumulado". Verifica-se, ainda, que a inovação não é percebida como fator de diferenciação competitiva, devido à falta de mecanismos de proteção, como patentes, por exemplo (PIRES; MARCONDES, 2004). 
Por meio de uma abordagem qualitativa, descritiva, exploratória e estudo de caso, busca-se analisar o processo da inovação aberta no ambiente de uma instituição financeira de varejo, uma das maiores e mais importantes instituições financeiras da América Latina, líder de mercado em muitos segmentos, e que tem gerado inúmeras inovações ao longo de sua existência.

A estrutura do presente artigo está organizada da seguinte forma: na sessão 1 introdução são apresentados os elementos que norteiam a pesquisa, como a problematização, objetivos, justificativa e principais temas de pesquisa; na sessão 2 é apresentada a fundamentação teórica sobre os temas inovação aberta e inovação aberta em sistemas financeiros; a sessão 3 trata dos procedimentos metodológicos adotados; na sessão 4 é discutida a análise dos dados, que compreende o contextualização da gestão da inovação na instituição estudada, e análise das categorias: modelo de gestão da inovação atual, as principais fontes de obtenção de inovações, e ambiente organizacional voltado à inovação aberta; a sessão 5 apresenta a discussão dos principais resultados; a sessão 6, as considerações finais do artigo e; por fim, as referências utilizadas.

\section{REFERENCIAL TEÓRICO}

\subsection{INOVAÇÃO ABERTA}

O termo inovação aberta foi proposto por Chesbrough (2003), em seu livro Open Innovation: The New Imperative For Creatingand Profiting from Technology, que tratou de casos de empresas como Xerox, IBM e Intel. O autor sintetizou diversas correntes teóricas já existentes, enfatizando, porém a questão da abertura e compartilhamento das informações da empresa para fora dela. O processo de inovação passa a explorar simultaneamente recursos internos e externos à empresa.

A inovação aberta surge como alternativa, supondo que as empresas devem usar ideias internas e externas, de acordo com seu modelo de negócio. Uma empresa deve, segundo Lindegaard (2011, p. 17), "selecionar e usar os tipos certos de Inovação Aberta - aqueles que se alinham melhor com as necessidades específicas, objetivos e complexidade tecnológica e comercial de sua organização" As empresas devem usar ideias e tecnologias externas, assim como caminhos externos para o mercado, para avançar em seus projetos de inovação. As iniciativas de inovação devem beneficiar-se de ideias, capacidades e apoio de outras empresas, sem comprometer segredos corporativos legítimos (HERZOG; LEKER, 2011).

O modelo de inovação aberta, nas palavras de Piatto, Bernardes e Moraes (2010, p. 2), “considera a inovação como um processo orientado à formação de redes colaborativas e de relacionamento onde projetos, tecnologias, patentes ou licenças de pesquisas em qualquer estágio de desenvolvimento podem ser adquiridas, vendidas ou desenvolvidas em conjunto com outras instituições”. Para isso, novas competências precisam ser desenvolvidas, a fim de transpor as fronteiras da empresa, através da aceitação de atores externos, em forma de parcerias e criação de valor (CHESBROUGH; APPLEYARD, 2007).

O modelo conceitual da inovação aberta está no fato de que, por mais maduras que sejam as atividades de $\mathrm{P} \& \mathrm{D}$ da organização, se ela for fechada, é incapaz de acompanhar a "dinâmica da criação e difusão de conhecimento", que é característica principal da sociedade atual, baseada em relacionamentos em rede. Segundo Chesbrough et al. (2006), para sobreviver nestes contextos complexos, é necessário que as empresas se conectem em redes de colaboração, intensificando o fluxo, a produção e a absorção de conhecimento novo, o desenvolvimento de novas tecnologias, a identificação de novos usos para tecnologias existentes, a comercialização de novos produtos e serviços ou, 
simplesmente, o acesso a novas ideias, interpretações e desenvolvimentos tecnológicos e científicos (PIRES; TEIXEIRA; HASTENREITER FILHO, 2012).

Chesbrough et al. (2006) defende que empresas baseadas no modelo de inovação fechada tem certa resistência a incorporar tecnologias desenvolvidas fora da empresa. Possui foco nas capacidades internas da organização, e somente o P\&D interno pode transcorrer as etapas do funil de inovação, deixando a empresa apenas no caso de lançamento do produto ao mercado. De acordo com Diehl e Ruffoni (2012, p. 28), "isso representa um risco, dada à elevada velocidade de desenvolvimento do conhecimento científico e tecnológico, a qual é uma das principais características do atual paradigma tecnológico vigente, o da Tecnologia da Informação e Comunicação".

A inovação aberta tende a adquirir um "status paradigmático", de acordo com Chesbrough (2012a, p. 59), pois impõe uma nova lógica, na qual "ideias de valor podem vir de dentro ou de fora da organização" podendo chegar ao mercado através de "esforços internos ou externos à organização com o mesmo grau de importância". Nesse sentido, se faz necessário, segundo Piatto, Bernardes e Moraes (2010, p. 2), "um novo desenho organizacional com novas rotinas para o aproveitamento e integração e transformação de conhecimentos internos e externos em inovação e geração de valor para a organização e para o mercado" chamado de plataforma de inovação aberta.

Segundo Chesbrough (2007), a abordagem da inovação aberta apresenta vantagens para a empresa, entre elas: habilidade de se alavancar com P\&D desenvolvidos com investimentos de terceiros; expandir o alcance e capacidade para gerar novas ideias e tecnologias; oportunidade de redirecionar recursos internos para a prospecção, triagem e gestão da implementação; potencialização do retorno sobre os investimentos em P\&D, através do licenciamento de patentes subutilizadas; maior senso de urgência no trato das ideias ou tecnologias (usá-las ou descarta-las); capacidade de realizar pesquisas estratégicas com baixo nível de risco e recursos e; possibilidade de extensão e/ou diversificação do negócio, criando-se novas alavancas para crescimento.

A estratégia aberta equilibra as forças de criação de valor que podem ser encontrados em indivíduos criativos, comunidades de inovação e iniciativas de colaboração com a necessidade de capturar valor, a fim de sustentar a participação contínua e apoio a essas iniciativas. Os conceitos tradicionais de estratégia de negócios, ou subestimam o valor da invenção e coordenação abertas, ou ignoram-os completamente. As iniciativas de inovação aberta tendem a enfrentar desafios reais e sérios para a sua capacidade de se sustentar ao longo do tempo. A questão de sustentabilidade remete a estratégia de negócio tradicional, que pode fazer contribuições importantes, mitigando riscos. Propõese uma nova abordagem para a estratégia de abertura que equilibre os princípios da estratégia de negócio tradicional, com a promessa de inovação aberta (CHESBROUGH; APPLEYARD, 2007).

\subsection{INOVAÇÃO ABERTA EM SERVIÇOS FINANCEIROS}

A natureza da demanda tem se alterado radicalmente na última década, criando clientes mais exigentes, infiéis e maduros. Os clientes escolhem os produtos a partir de um contexto universal, mas ao mesmo tempo esperam muito mais dos serviços de seu banco. Conceitos como consultoria e gestão do relacionamento tornam-se fundamentais. Além de produtos inovadores a preços competitivos, existe a necessidade de combinar produtos de terceiros com os produtos e serviços próprios do banco. Alguns bancos estão implementando novos modelos de negócios para a venda de produtos e serviços, abrindo o portfólio de produtos, oferecendo produtos próprios, em combinação com produtos de terceiros (FASNACHT, 2009). 
Abordagens mais recentes, como a de Fasnacht (2009), adaptaram conceitos de inovação aberta para os serviços financeiros. $\mathrm{O}$ autor criou um dos primeiros modelos de negócios abertos, voltados para o contexto da indústria de serviços financeiros, adaptando e aprimorando conceitos básicos de inovação aberta, desenvolvendo o modelo a fim de auxiliar a compreender a dinâmica da indústria no setor bancário, aproveitando a energia organizacional por meio de inovação aberta para sustentar o crescimento rentável.

A inovação aberta não tem sido muito praticada pelas instituições financeiras. A maior parte das inovações é relativa à criação de produtos financeiros complexos. A prática de imitação é comum no segmento bancário e o produto financeiro não dispõe de mecanismos de proteção, como patentes ou marcas registradas, o que limita sua vantagem competitiva neste sentido (PIRES; MARCONDES, 2004). Empresas de fora do setor vem ganhado espaço cada vez maior, como Paypal e Google, por exemplo (BARRI et al., 2014).

Existem alguns fatores que influenciam a prática da inovação em serviços bancários. Um dos principais é a forte regulamentação que o setor está submetido. Muitos dos produtos/serviços comercializados pelos bancos são normatizados, pelo Banco Central, Governo Federal ou órgãos a eles vinculados. Exemplos disso são: o microcrédito, o crédito imobiliário, o crédito agrícola, a seguridade, as aplicações financeiras, entre outros (FACÓ; SIMANTOB, 2009).

Por sua vez, a regulamentação imposta aos bancos pode dificultar o processo de inovação. As organizações inovadoras devem ser mais rápidas para se adaptar às mudanças externas. Para serem capazes de responder rapidamente a mudanças externas, os executivos devem buscar ajuda e estruturas que facilitam a flexibilidade, criatividade e participação. Esta estrutura é influenciada por pressões ambientais internas e externas, que levam a empresa a promover alterações, em forma de respostas organizacionais (FASNACHT, 2009).

Com as novas tecnologias se espalhando rapidamente por toda a cadeia, o modelo de negócios que a empresa adota torna-se mais importante que a tecnologia. As empresas precisam adotar uma perspectiva estratégica e ciclos de decisões rápidos para acompanhar as mudanças, segundo Barri et al., (2014, p. 9), "as instituições financeiras precisam ser capazes de seguir em frente, abandonar o que não está funcionando, e verificar se eles estão sempre ouvindo seus clientes".

Os investimentos em inovações nos bancos normalmente estão relacionados à tecnologia da informação e comercio eletrônico, que contribuem para a redução dos custos, geram flexibilidade e agilidade, aumentando seu poder competitivo. Segundo Barbieri e Simantob (2009), os bancos são considerados pioneiros em adotar soluções tecnológicas, no entanto, as inovações geradas são internas e raramente chegam aos clientes. Aos poucos, chegam aos clientes, em estágio de implementação e difusão, novas tecnologias como, home banking, internet banking e mobile banking (CERNEV; DINIZ; JAYO, 2009).

A inovação aberta leva em consideração a colaboração além das fronteiras da empresa, incluindo concorrentes, exigindo uma aberta e inovadora cultura organizacional, enfatizando a aprendizagem organizacional. De acordo com Fasnacht (2009, p. 90), "a construção de uma aprendizagem e cultura de inovação organizacional em toda a organização é, portanto, considerada como um fator chave de sucesso para mudança organizacional e de renovação".

Nesse contexto, são necessárias novas práticas de gestão dinâmicas, tais como pensamento ambidestro, atitude intraempreendedora e uma visão sistêmica e holística sobre a empresa. A pressão por redução de custos no setor financeiro é muitas vezes à custa da qualidade dos serviços, do crescimento e da inovação. A ambidestria pressupõe a habilidade de se reduzir custos, criando inovações de valor. Já o intraempreendedorismo relaciona-se à prática de usar as habilidades que se concentram 
em inovação e criatividade para transformar ideias de negócio em um empreendimento rentável dentro da organização. Dada complexidade do negócio financeiro global, é necessária uma visão interdisciplinar e sistêmica sobre as principais forças econômicas, políticas, sociais e tecnológicas atualmente trabalhando no mundo. Ao abrir-se a uma nova forma de organização, também se torna necessária uma cultura de inovação aberta e de capital social (FASNACHT, 2009).

\section{PROCEDIMENTOS METODOLÓGICOS}

Considerando os objetivos propostos e suas particularidades, a pesquisa adotou a abordagem qualitativa, por meio de um estudo descritivo e exploratório, e como método, o estudo de caso.

$\mathrm{O}$ estudo de caso busca investigar um fenômeno contemporâneo em profundidade e em seu contexto de vida real, especialmente quando os limites entre o fenômeno e o contexto não são claramente definidos, o que exige, muitas vezes, o entendimento de condições contextuais pertinentes ao objeto em estudo (YIN, 2005). Como o método requer a utilização de múltiplas fontes de evidência, foram utilizadas fontes documentais, entrevistas e observações.

Em relação às fontes documentais, foram analisados documentos internos e instruções normativas da instituição financeira. Quanto à entrevista, foi adotada a modalidade aberta, através de um roteiro semiestruturado aplicado a dois executivos da Diretoria de Estratégia e Organização, dois assessores da Diretoria de Tecnologia, um executivo da Superintendência Regional de Varejo, e um funcionário da rede de agências. Também foi entrevistado um dirigente de empresa cliente da instituição financeira, totalizando 7 entrevistas, conforme ilustrado no Quadro 1.

Quadro 1 - Resumo das entrevistas realizadas

\begin{tabular}{|l|l|l|c|}
\hline Entrevistado(s) & Sigla & Local & Duração \\
\hline Executivos da Diretoria de Estratégia e Organização. & $\begin{array}{l}\text { Entrevistado 1 (E1) } \\
\text { Entrevistado 2 (E2) }\end{array}$ & Brasília - DF & $01: 31: 19$ \\
\hline Assessores da Diretoria de Tecnologia. & $\begin{array}{l}\text { Entrevistado 3 (E3) } \\
\text { Entrevistado 4 (E4) }\end{array}$ & Brasília - DF & $00: 42: 08$ \\
\hline Superintendente Regional de Varejo. & Entrevistado 5 (E5) & Chapecó - SC & $00: 32: 00$ \\
\hline Funcionário da rede de agências. & Entrevistado 6 (E6) & Pinhalzinho - SC & $00: 45: 15$ \\
\hline $\begin{array}{l}\text { Dirigente de Empresa cliente da instituição } \\
\text { financeira. }\end{array}$ & Entrevistado 7 (E7) & Pinhalzinho - SC & $00: 22: 52$ \\
\hline
\end{tabular}

Fonte: elaborado pelo autor

Em relação à observação, foi utilizada a modalidade participante, com técnicas guiadas, realizadas nas diretorias de estratégia e organização e diretoria de tecnologia, que possibilitou inúmeros questionamentos e foi possível ter acesso a documentos importantes que deram maior sustentação ao relatório.

Os dados oriundos das entrevistas, análise documental e das observações alimentaram as categorias de análise, ilustradas no Quadro 2.

Quadro 2 - Categorias de análise formuladas a partir do referencial teórico

\begin{tabular}{|c|l|l|}
\hline Categorias & \multicolumn{1}{|c|}{ Subcategorias } & \multicolumn{1}{|c|}{ Principais autores } \\
\hline $\begin{array}{c}\text { Modelo de Gestão } \\
\text { da Inovação }\end{array}$ & $\begin{array}{l}\text { • Modelo de gestão da inovação adotado; } \\
\text { • O processo de inovação (geração, seleção e } \\
\text { implementação); }\end{array}$ & $\begin{array}{l}\text { Tigre (2006); Van Der Meer } \\
\text { (2007); Tidd; Bessant; Pavitt } \\
\text { (2008). }\end{array}$ \\
\hline
\end{tabular}




\begin{tabular}{|c|c|c|}
\hline Categorias & Subcategorias & Principais autores \\
\hline & $\begin{array}{l}\text { - Forma que ocorre a seleção e aproveitamento das ideias para } \\
\text { que se transformem em inovações. }\end{array}$ & \\
\hline $\begin{array}{l}\text { Fontes de obtenção } \\
\text { de inovações } \\
\text { (internas e } \\
\text { externas). }\end{array}$ & $\begin{array}{l}\text { - Formas de relacionamento utilizados com canais externos } \\
\text { de informação (clientes, fornecedores, universidades, ICT's, } \\
\text { concorrentes, governo, etc.); } \\
\text { - Formas de relacionamento utilizados com canais internos de } \\
\text { informação; } \\
\text { - Participação do cliente na construção das inovações } \\
\text { (crowdsourcing, colaboração em massa e cocriação). }\end{array}$ & $\begin{array}{l}\text { Chesbrough (2003, 2006, 2007, } \\
\text { 2011, 2012A, 2012B); Herzog; } \\
\text { Leker (2011); Howe (2006); Von } \\
\text { Hippel (2005); Ferro (2010). }\end{array}$ \\
\hline $\begin{array}{l}\text { Ambiente } \\
\text { organizacional } \\
\text { voltado à inovação } \\
\text { aberta. }\end{array}$ & $\begin{array}{l}\text { - Cultura voltada à inovação aberta; } \\
\text { - Estrutura organizacional flexível; } \\
\text { - Modelos de negócios abertos, voltados para o contexto da } \\
\text { indústria de serviços financeiros. }\end{array}$ & $\begin{array}{l}\text { Tidd, Bessant E Pavitt (2008); } \\
\text { Chesbrough (2012a); Fascnacht } \\
\text { (2009); Barri et al. (2014). }\end{array}$ \\
\hline
\end{tabular}

Fonte: elaborado pelo autor (2015)

O processo de codificação e categorização foi realizado com o auxílio do software Nvivo versão 10.

\section{APRESENTAÇÃO E ANÁLISE DOS DADOS}

A seguir, será apresentada a descrição sobre o contexto da inovação na instituição objeto de estudo e, posteriormente, a análise de conteúdo (BARDIN, 2009) a partir das categorias definidas a priori e consubstanciadas na literatura pesquisada.

\subsection{O CONTEXTO DA INOVAÇÃO NA INSTITUIÇÃO}

Identificou-se que a instituição financeira sofreu influência sobre as mudanças significativas ocorridas na história do País. Introduziu diversas inovações no sistema bancário responsáveis por impactos importantes, entre elas o cheque especial, a compensação de cheques e outros papéis em 24/48 horas, a Cédula de Produtor Rural (CPR), o mobile payment, entre outros (BARBIERI; SIMANTOB, 2009).

É considerada uma das maiores instituições financeiras do Brasil e da América Latina, líder em ativos totais, e uma das maiores e mais sólidas instituições financeiras do mundo. (BANCO CENTRAL DO BRASIL, 2014). No Brasil, são mais de 4 mil agências e mais de 40 mil caixas eletrônicos e, no exterior, possui mais de 50 pontos de atendimento.

A Tabela 1 ilustra as categorias que surgiram a partir das fontes de evidência consultadas, em especial, os sujeitos de pesquisa quando questionados sobre o atual contexto da inovação na instituição:

Tabela 1 - Total de ocorrências de códigos da categoria contexto da inovação

\begin{tabular}{lcc}
\hline \multicolumn{1}{c}{ Categorias } & Ocorrências & $\begin{array}{c}\text { Palavras } \\
\text { codificadas }\end{array}$ \\
\hline Principais tipologias de inovação presentes & 17 & 1.181 \\
Como a inovação ocorre na instituição & 11 & 753 \\
Principais atributos da instituição inovadora & 08 & 426 \\
\hline Total & 36 & \\
\hline
\end{tabular}

Fonte: elaborada pelos autores com auxílio do software Nvivo versão 10 
Evidencia-se que a instituição financeira expandiu nos últimos anos, aumentando a complexidade do modelo de negócio por meio de aquisições e parcerias, atuando em diversos setores novos, como o mercado imobiliário, por exemplo. Dentre os principais fatores que impulsionam a necessidade de inovação, de acordo com o E1, estão a "redução de spread, evolução do mercado de consumo, os clientes estão mais exigentes, e necessidade de melhoria dos índices de eficiência", sendo que a inovação está presente e é muito utilizada para "melhorar a eficiência operacional", que pode ser caracterizada como inovação em processo, de acordo com o Manual de Oslo (OCDE, 2005).

Percebe-se que as principais tipologias de inovações presentes na instituição financeira estão relacionadas a produtos e serviços, especialmente para melhorar a eficiência operacional (processos), e corroboram com as três formas genéricas caracterizadas por Fasnacht (2009), para o setor de serviços financeiros: inovação de produtos e serviços, inovações de processos e inovações comuns à função organizacional. Outro aspecto observado, é que os produtos e serviços bancários são fáceis de copiar. Tais observações se confirmam nos estudos realizados por Pires e Marcondes (2004) e Tidd, Bessant e Pavitt (2008).

$\mathrm{Na}$ opinião do E1, a instituição financeira tem sido reconhecida como inovadora, criando vários produtos, como por exemplo, o "pague sem" e a "conta de pagamento", e o cliente tem percebido estas inovações. O E5 destaca inúmeras inovações importantes, como o custeio renovável, uma inovação importante que trouxe inúmeros benefícios aos agricultores, o autoatendimento via mobile, o uso da biometria nos terminais de autoatendimento, e inúmeras melhorias nas transações via internet, através de soluções inovadoras de segurança.

Foi possível identificar iniciativas de inovação, porém dispersa, como, por exemplo, a diretoria de estratégia e organização incentiva e patrocina atividades de inovação no banco, porém cada área define sua estratégia de forma isolada. Foram desenvolvidas inúmeras iniciativas dispersas em várias diretorias, que culminaram na criação de soluções inovadoras, chamadas de campanhas de inovação. Percebe-se que se torna necessário um movimento para organizar o processo, através da criação de uma estrutura adequada par a gestão da inovação, conforme preconizam Bruno-Faria e Fonseca (2014); Engenhof e Balestrin (2008), Ferro (2010), Tidd, Bessant e Pavitt (2008), e Van der Meer (2007).

Interessante observar o relato do E3: "a grande vantagem é que os outros bancos estão no mesmo patamar. Os bancos estão de certa forma, acomodados, praticando apenas ações pontuais. Nenhum deles começou a investir na inovação de forma estratégica". Tal situação corrobora com Fasnacht (2009), em relação à necessidade de adoção de novas estratégias de inovação pelo setor financeiro. Além disso, constata-se que a maioria das ações tem se concentrado no desenvolvimento de soluções tecnológicas, reforçado por Barbieri e Simantob (2009) e Barri et al. (2014).

\subsection{MODELO DE GESTÃO DA INOVAÇÃO ATUAL}

A Tabela 2 apresenta o total de ocorrências de códigos da categoria modelo de gestão de inovação, e suas subcategorias:

Tabela 1 - Total de ocorrências de códigos da categoria modelo de gestão da inovação

\begin{tabular}{lcc}
\hline \multicolumn{1}{c}{ Subcategorias } & Ocorrências & $\begin{array}{c}\text { Palavras } \\
\text { codificadas }\end{array}$ \\
\hline Aproveitamento de ideias/inovação & 27 & 758 \\
Processo de inovação & 19 & 1.757 \\
Modelo de gestão da inovação adotado & 13 & 2.491 \\
\hline Total & 59 & 5006 \\
\hline
\end{tabular}

Fonte: elaborada pelos autores com auxílio do software Nvivo versão 10 
Evidencia-se que a instituição utiliza diversas ferramentas de colaboração interna, caracterizadas como iniciativas de inovação aberta, porém elas ocorrem de forma limitada e discreta, necessitando que algumas lacunas sejam superadas a fim de que o conhecimento flua de forma mais intensa (DIEHL; RUFONI, 2012).

No quadro 3, são apresentadas as principais ferramentas de inovação identificadas.

\begin{tabular}{|l|l|}
\hline \multicolumn{2}{l}{ Quadro 3 - Ferramentas corporativas de inovação } \\
\hline Nome da ferramenta & Descrição \\
\hline Blog de Ideias & Ideação com colaboradores internos. O código fonte da ferramenta é do Banco. \\
\hline Fórum Inovando com o Cliente & $\begin{array}{l}\text { Plataforma de interação com clientes convidados a contribuir no processo de } \\
\text { inovação em temas e projetos específicos }\end{array}$ \\
\hline Laboratório de Inovação & $\begin{array}{l}\text { Metodologia de inovação que utiliza técnicas de design thinking para geração de } \\
\text { ideias e projetos em temas específicos }\end{array}$ \\
\hline
\end{tabular}

Fonte: Documentos disponibilizados pela instituição pesquisada

Algumas campanhas de inovação foram realizadas contando com a participação de colaboradores internos, utilizando-se a ferramenta "Blog de Ideias". Como resultado da ação, foram sugeridas cento e quatro ideias, classificadas em relação ao grau de novidade envolvido, de acordo com Bessant e Tidd (2009) e OCDE (2005), como inovações incrementais (novas para a empresa) e inovações disruptivas (novas para o mercado).

Outro exemplo de campanha pela perspectiva da inovação aberta foi a utilização da ferramenta "Fórum Inovando com o Cliente". Neste fórum, alguns clientes eram convidados a testar, opinar, compartilhar ideias, pensamentos e experiências. Também neste canal, pode-se testar um protótipo chamado "Plataforma Empresas do Futuro", que é um ambiente virtual construído junto com os clientes, uma iniciativa que pode ser caracterizada como uso de inteligência coletiva ou crowdsourcing (EBOLI; DIB, 2010; HOWE, 2006).

Por meio do Fórum Inovando com o Cliente (princípio de inovação aberta), foi possível chegar a um canal capaz de atender às necessidades do cliente, e ao mesmo tempo reduzir tempo de atendimento e custo. Os autores Chesbrough (2006) e Engenhoff e Balestrin (2008) reforçam as afirmações, através da importância dada à origem do conhecimento interno e externo, advindo do uso da inovação aberta.

Segundo o E1, a instituição financeira caminha para um "modelo de negócio digital". Mais uma vez é enfatizado, que o novo programa de inovação do Banco, será focado no relacionamento com o cliente e no modelo de negócio. O E1 ressalta ainda que este movimento de inovação não é excludente, pois é fundamental continuar inovando em produtos e processos.

A terceira ferramenta utilizada pela instituição, Laboratório de Inovação, consiste em uma metodologia que utiliza a técnica do design thinking, conforme relato do E1, "essa aqui é a metodologia que nós usamos dentro do Banco para projetos de inovação, que é a metodologia conhecida mundialmente como design thinking: inspira, idea, prototipa e desenvolve", conforme pode ser observada na Figura 1.

Figura 1 - Metodologia do design thinking utilizada pela instituição

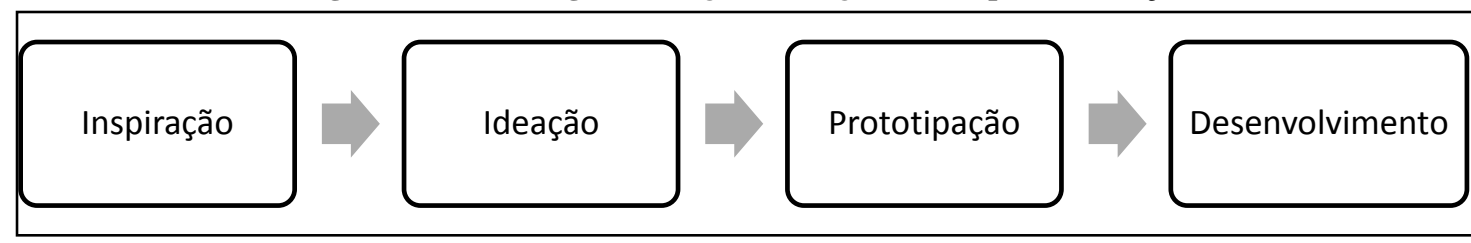

Fonte: elaborada pelo autor 
Conforme Pinheiro e Alt (2011, p. 5), "mais do que uma metodologia, design thinking é um novo jeito de pensar e abordar problemas. Um novo modelo mental". A premissa do design thinking é o foco no consumidor. "Ainda, o design thinking busca o equilíbrio entre o que é desejável para as pessoas, financeiramente interessante para o negócio e, por fim, prega que todo resultado seja passível de ser produzido e implementado".

A diretoria de tecnologia do Banco também utiliza a metodologia do design thinking para condução dos projetos de inovação, conforme relatos do E3 e E4, em especial as fases de ideação, prototipação de desenvolvimento. O E3 relata o funcionamento do processo de inovações da diretoria de tecnologia. Na entrada do funil está a prospecção de vigilância tecnológica, as campanhas internas de ideias, fornecedores, universidades e Institutos de ciência e tecnologia (ICT). Todas correspondentes à fase de ideação. Depois existem dois estágios (chamados de stagegates) que fazem o filtro das ideias através de uma ferramenta desenvolvida em Excel.

Ainda, segundo o E3, os "stagegates" que são pontos de tomada de decisão, na qual uma ideia pode passar ou não para a outra fase. Todas as ideias são registradas neste processo. Segundo Tidd, Bessant e Pavitt (2008, p. 401), trata-se de um "processo estruturado e organizado em estágios", através da inserção de "portões" em estágios fundamentais do projeto, e a sua revisão com base em critérios bem claros e definidos. Se o projeto atender aos critérios definidos, passa para outra fase ou, caso contrário, é abortado ou reorientado.

Outra iniciativa de inovação é adotada pela Diretoria de Tecnologia, é o Mosaico de Ideias, uma campanha de ideias que conta com a colaboração de todos os colaboradores da diretoria. Segundo o E3, é um tipo de crowdsourcing, ou seja, utiliza inteligência e conhecimento coletivo. Apesar de possui caráter colaborativo, verifica-se que o fluxo de informações ocorre apenas internamente. Segundo Howe (2006), o crowdsourcing delega atividades antes executadas por funcionários, para uma rede de pessoas, de forma aberta.

$\mathrm{Na}$ Diretoria de Tecnologia, existem os Workshops de inovação, que também utilizam a metodologia do design thinking, com vistas a resolver problemas de várias diretorias, entendendo e trazendo a solução. Segundo o E3, a realização dos workshops:

(...) é inovação aberta também, que a gente chama diversas áreas. Geralmente no workshop tem gente de diversas diretorias, chama gente da rede de agências, assim três, quatro funcionários de agência com perfil diferente, com olhar diferente, que ajuda a gente a desenvolver essa solução. (ENTREVISTADO E3).

O papel da área de gestão da inovação, dentro da instituição financeira analisada, é promover, apoiar e incentivar a inovação dentro da organização. A área fornece as ferramentas necessárias, dicas, métodos e técnicas para fazer a ideação. Nesse sentido, cada diretoria do Banco tem autonomia para o desenvolvimento de iniciativas de inovação. Por exemplo, a área de gestão de pessoas, a Diretoria de Micro e Pequenas Empresas, a Diretoria de Tecnologia, a Diretoria de Governo, a Diretoria de Atacado, etc.

Cada diretoria tem as suas campanhas de inovação, e o papel da área de gestão consiste em dar suporte através de metodologias, ferramentas e treinamento necessário para que o processo de inovação ocorra. Depois de selecionadas as ideias, um grupo de funcionários é reunido em um laboratório para discutir e selecionar as melhores ideias. Depois de selecionadas, um comitê aprova e prioriza algumas.

Desde 2008, a instituição possui um programa de inovação formal, com orçamento. Existe um projeto de revisão do programa de inovação da instituição financeira, ou seja, o modelo de gestão da inovação está sendo reformulado. Existe uma proposta, que passou pelas fases de diagnóstico, 
experimentação e para a sua implementação, depende de uma consultoria externa especializada validar o modelo. O processo de revisão do modelo iniciou no final de 2013, passando por vários meses de análise devido à alta complexidade da organização.

O E1 entende que deve ser adotado um modelo que não atue nos dois extremos, ou seja, um modelo que apoia as áreas, mas deixa o processo de inovação livre. Um modelo intermediário que fornece a metodologia, as ferramentas e capacitação. A área deve funcionar como impulsionadora das demais diretorias e das demais áreas da instituição financeira. Essas áreas, juntamente com seus clientes (inovação aberta), podem gerar inovações. O papel da área de gestão da inovação é, segundo o E1, ser "promotor e facilitador" de inovações. Tidd, Bessant e Pavitt (2008, p.98) sugerem que a tarefa de gerenciar a inovação é "complexa e incerta", mas também não deve ser vista apenas como um assunto de especialistas.

\subsection{AS PRINCIPAIS FONTES DE OBTENÇÃO DE INOVAÇÕES}

Constata-se que a instituição financeira possui fontes de informações externas, apesar de não estarem sistematizadas em todos os seus elementos. Os autores Diehl e Rufoni (2012) destacam que a inovação aberta tem ocorrido de forma limitada nas organizações, exigindo adoção de mecanismos para que as ideias fluam de forma mais intensa. As principais fontes de informação identificadas no processo de inovação pela organização foram: clientes, funcionários, fornecedores, universidades e empresas parceiras. Porém, observa-se que as fontes de informação têm sido pouco exploradas, e não ocorre de forma sistematizada, estruturada e regular.

A Tabela 3 apresenta o total de ocorrências de códigos da categoria principais fontes de obtenção de inovações, e suas subcategorias:

Tabela 3 - Total de ocorrências de códigos da categoria principais fontes de obtenção de inovações

\begin{tabular}{lcc}
\multicolumn{1}{c}{ Subcategorias } & Ocorrências & $\begin{array}{c}\text { Palavras } \\
\text { codificadas }\end{array}$ \\
\hline Formas de relacionamento canais externos de informação & 32 & 2.008 \\
Participação do cliente na construção das inovações & 16 & 1.008 \\
Formas de relacionamento canais internos de informação & 14 & 1.080 \\
\hline Total & 62 & 4096 \\
\hline
\end{tabular}

Fonte: elaborada pelos autores com auxílio do software Nvivo versão 10

No âmbito da inovação aberta, a instituição financeira participa de redes e fóruns de inovação, como o Fórum de Inovação da Fundação Getúlio Vargas (FGV), que possui parcerias com outras universidades, entre elas, a Universidade de Brasília (Unb), a Universidade do Vale do Rio dos Sinos (Unisinos), a Universidade Estadual de Campinas (Unicamp) e a Fundação Instituto de Pesquisas Contábeis, Atuariais e Financeiras (Fipecaf). Existem também, diversos parceiros na área de inovação, como consultorias e empresas que prestam serviços para o Banco, porém, apresentam-se mais como um esforço de inovação da organização, do que uma abertura para o desenvolvimento da inovação em parceria.

Percebe-se que na Diretoria de Tecnologia, a inovação aberta encontrou terreno mais fértil. Devido à necessidade de constante inovação tecnológica nos bancos (BARBIERI; SIMANTOB, 2009; PIRES; MARCONDES, 2004), com o desenvolvimento de produtos e serviços, muitas vezes em parceria, esta unidade tem uma melhor percepção dos benefícios advindos da adoção da inovação aberta. Observa-se no relato do E3: "se for pensar, por exemplo, na área de TI que a gente depende muitas vezes 
das nossas soluções e também de parceria com outros fornecedores, com soluções de terceiros, que compõe parte das nossas soluções". Além das parcerias com universidades, identificou-se parcerias com Institutos de Ciência e Tecnologia, que vem trabalhando com projetos para desenvolver a TI aberta, e também projetos na área de Telecomunicações.

Ainda na Diretoria de Tecnologia, foi possível identificar uma ferramenta que, segundo o E3 "não deixa de ser uma unidade de crowdsourcing" (HOWE, 2006), chamada de Innovation Day, um dia voltado ao desenvolvimento de ideias relacionadas a determinado assunto. Essa iniciativa de inovação aberta consiste na utilização de startups para trabalhar desde a ideação, até um protótipo tangível, que possa ser mostrado e até vendido para o Banco.

Algumas iniciativas inovação aberta tem acontecido com maior frequência com os clientes, com destaque para campanhas realizadas com o público jovem e com as micro e pequenas empresas, a fim de se captar ideias para se pensar no "banco do futuro", conforme relatos do E1. As plataformas de colaboração criadas em ambiente web convidam o cliente a inovar com o Banco - cocriação (PRAHALAD; RAMASWAMY, 2003). A proposta é a criação de um canal de atendimento totalmente digital, sem que o cliente precise ir à agencia. O cliente escolhe se quer ter o atendimento digital, ou quer ser atendido por um gerente de relacionamento na agencia.

No caso da instituição financeira analisada, a assertividade para o lançamento de um novo canal de atendimento só foi possível por que foi ouvido o cliente, conforme relata o E1, "a gente tinha uma percepção, sabíamos que o caminho era esse, mas se a gente não ouvisse o cliente, a gente ia fazer outra coisa. Ou ia demorar, você ia colocar um troço desses e ninguém ia usar". Na inovação aberta em serviços financeiros o foco reside no cliente, através de um processo consultivo, ao invés da simples venda de produtos (FASNACHT, 2009).

O interessante é que a visão dos entrevistados das diretorias do Banco (E1, E2, E3 e E4), assim como das unidades operacionais de varejo (E5 e E6), e o dirigente de empresa cliente (E7), acreditam que é possível e necessária, a utilização da inovação aberta, principalmente do estreitamento de relações com os clientes. Segundo Fasnacht (2009), para o setor de serviços financeiros é essencial uma estrutura flexível e voltada às necessidades dos clientes. O E7 relata que desconhece qualquer iniciativa de inovação da instituição financeira analisada, de que forma acontece, ou mesmo se existe uma área responsável pela inovação dentro do Banco. Porém enfatiza que um Banco concorrente, possui um canal que permite que o cliente dê sua contribuição em alguns temas específicos.

Percebe-se, na fala do E5, a existência de restrições em relação ao compartilhamento de informações, típicos do setor bancário:

É assim. Externamente eu acho que tem um certo resguardo né, digamos assim né, primeiro, a questão se houver alguma coisa do sigilo bancário, tem que ser seguido a lei, se não tem sigilo bancário, ai é uma questão de confiança entre os parceiros, se é possível você abrir algo que ainda não está totalmente estudado, implementado até o parceiro. (ENTREVISTADO E5).

Novamente, vêm à tona questões que fazem com que este tipo de indústria tenha que adotar um sistema "híbrido" entre inovação fechada e inovação aberta, conforme relatado por Chesbrough (2012a), devido à forte regulamentação imposta pela legislação e pelo Banco Central. Em contrapartida, o E6 acredita que os parceiros externos, em especial as universidades, podem contribuir significativamente com a expertise necessária para a construção de soluções inovadoras.

A importância da participação do colaborador interno é enfatizada pelo E5, assim como o pelo E6. Ambos confirmam que o acesso a canais de colaboração internos de ideias pode auxiliar a empresa a atingir seus objetivos, principalmente com a pessoas envolvidas no desenvolvimento de determinado 
produto ou serviço. O E5 complementa ainda que os funcionários são "o elo entre a empresa e o cliente" e reforça que, "se existe alguém que tem que conhecer muito bem tudo que está rodando de inovação dentro do banco são nossos funcionários, até porque os nossos funcionários são nossos clientes e também poderão auxiliar na avaliação do que se está propondo inovar". Por outro lado, o E5 desconhece a existência dos canais de colaboração internos citados. Percebe-se que eles têm sido mais utilizados como ferramenta de colaboração pelas diretorias do Banco.

Percebe-se a preocupação da instituição financeira em ampliar o processo de forma mais robusta, através de novas parcerias de inovação aberta. Mas os principais entraves, aparentemente, estão na questão de tempo, na falta de uma equipe que gerencie o processo de inovação, e em limitações orçamentárias. As instituições financeiras, de forma geral, esperam resultados de curto prazo. Porém quando se fala em inovação, deve-se primeiramente trabalhar com a cultura organizacional. Neste quesito, os entrevistados foram unânimes em reconhecer que o principal aspecto em um modelo de gestão da inovação é a cultura voltada para a inovação. As empresas que pretendem adotar um modelo de gestão da inovação aberta têm que ter certa tolerância a riscos (FERRO, 2010). Percebe-se na fala de alguns entrevistados (E3 e E4), que nem tudo dentro da instituição financeira deve ser compartilhado.

Por outro lado, o E3 alerta que na hora que aparecerem outros entrantes no mercado, como o Paypal, por exemplo, vai forçar as instituições financeiras a adotarem a inovação aberta. Por enquanto o setor financeiro é altamente regulamentado, com pouca concorrência externa. Se os bancos seguirem as normas impostas pelo Banco Central e fizerem tudo certo, não tem como não ser lucrativo. Mas no momento que surgirem novos entrantes, diferentes daqueles que os bancos estão acostumados, vai forçar os bancos a investir mais em inovação. Por que os outros entrantes já estão vindo com a inovação pronta, indo ao encontro do que diz Barri et al. (2014).

\subsection{AMBIENTE ORGANIZACIONAL VOLTADO À INOVAÇÃO ABERTA}

Um aspecto relevante observado no estudo foi a predominância de uma cultura organizacional conservadora. Outro fator que merece destaque é a inexistência de uma equipe ou estrutura responsável pela gestão da inovação. A disseminação das informações e a necessidade de uma equipe para conduzir o processo, são condicionantes para uma organização inovadora, segundo Tidd, Bessant e Pavitt (2008).

Em relação à disseminação da cultura da inovação, percebe-se a dificuldade das informações chegarem à rede de agências. Em especial nas diretorias entrevistadas, o assunto já está bem difundido, porém, percebe-se que o nível de conhecimento sobre as iniciativas de inovação perde força à medida que se desloca em direção ao cliente, ou seja, a rede de agências.

A Tabela 4 apresenta o total de ocorrências de códigos da categoria ambiente organizacional voltado à inovação e suas subcategorias:

Tabela 4 - Total de ocorrências de códigos da categoria ambiente organizacional voltado à inovação aberta

\begin{tabular}{lcc}
\hline Subcategorias & Ocorrências & $\begin{array}{c}\text { Palavras } \\
\text { codificadas }\end{array}$ \\
\hline Cultura voltada à inovação aberta & 46 & 1.161 \\
Estrutura organizacional flexível & 04 & 315 \\
Modelos de negócios abertos voltados para aos serviços financeiros & 17 & 558 \\
\hline Total & 36 & \\
\hline
\end{tabular}

Fonte: elaborada pelos autores com auxílio do software Nvivo versão 10 
$\mathrm{Na}$ instituição financeira analisada, observa-se uma estrutura hierárquica ainda muito voltada para o controle, e com foco interno. Provavelmente, seja uma característica comum à maioria das instituições financeiras. Também, conforme o E4, existem questões políticas e internas que criam uma resistência enorme às mudanças. Parte disso relaciona-se ao fato de ser um banco vinculado ao Governo Federal. Parte da estratégia corporativa da instituição financeira é atender as demandas governamentais, o que o leva muitas vezes a entrar em negócios não tão inovadores ou lucrativos. Isso não acontece nas instituições financeiras privadas.

Evidenciou-se ainda, que a área responsável pela gestão de pessoas na instituição financeira é peça chave para a se trabalhar os aspectos relacionados à cultura da inovação, através de treinamentos e capacitação nesta área, atuando em conjunto com os programas de inovação. Também a área de comunicação é importante e responsável pela disseminação das informações.

As diretorias mencionam que sabem o que precisa ser feito, mas a estrutura organizacional mostra-se muito complexa. Quando se pretende desenvolver uma solução tecnológica, por exemplo, o processo entre em uma fila. Isso acaba criando uma desvantagem competitiva para a organização, que não possui a mesma velocidade que o mercado. A gestão da inovação pretende resolver este problema, através da priorização da produção de projetos inovadores.

Muitos projetos em fase de desenvolvimento necessitam de parcerias externas (inovação aberta), porém, conforme relatos do E4:

Você tem uma ideia maravilhosa, mas depende de solução de terceiro. Ai você tem que licitar. Você não tem abertura, é um processo demorado, sabe você leva é coisa de anos, passa o tempo fácil, fácil. Então assim, o ideal é que a gente tivesse flexibilidade pra você fazer o protótipo inicial. (ENTREVISTADO E4).

Conforme relatos, as dificuldades são ocasionadas, parte pela estrutura organizacional atual, e parte pela legislação que se aplica à instituição financeira por ser engessada aos procedimentos burocráticos governamentais. Ainda, segundo relatos do E3, devido à legislação que se aplica ao Banco, dificilmente haveria parcerias sem a formalização de convênios. Por isso acredita-se que as parcerias externas tendem a se fortalecer mais com centros de pesquisa, mais aplicáveis às normas impostas à empresa. As parcerias diretas são mais difíceis de acontecer, ou seja, deve haver um meio legal ou instrumento formalizado.

A complexidade do organograma da instituição financeira a torna menos robusta para a criação de equipes voltadas à inovação. Ainda não se percebe a importância da criação de uma equipe voltada para a gestão da inovação. Muitas das áreas existentes dentro do Banco estão focadas em controles e processos internos. Não que não seja importante, mas o foco excessivo no controle e hierarquia tende a prejudicar um ambiente favorável a criação de novas ideias, e consequentemente à inovação. Da mesma forma, a percepção da rede de varejo, conforme o E5 e E6, também são de uma estrutura pesada e complexa. Porém acreditam que a falta de velocidade é compensada pela "alta qualidade dos produtos oferecidos" e também pela confiança na marca e solidez da instituição. Também tem a questão da ética e transparência muito forte envolvida nos processos, sendo uma instituição que segue à risca as leis.

Finalizando, foi realizada com o auxilio do software Nvivo a contagem de palavras existentes nas fontes de evidência consultadas. A Tabela 5 ilustra as dez palavras mais citadas e o seu respectivo número de ocorrências. Destaca-se a palavra inovação como a mais mencionada seguida das palavras banco, modelo, cliente, processo, ideais, área, eles, projeto e programa. A figura 2 ilustra a respectiva nuvem de palavra elaborada com o auxílio do software. 
Tabela 5 - Total de palavras codificadas

\begin{tabular}{ccc}
\hline Palavras & Ocorrências \\
\hline Inovação & 484 \\
Banco & 298 \\
Modelo & 173 \\
Cliente & 133 \\
Processo & 115 \\
Ideias & 104 \\
Área & 86 \\
Eles & 82 \\
Projeto & 82 \\
Programa & 77 \\
\hline
\end{tabular}

\section{Fonte: elaborada pelos autores com auxílio do software Nvivo versão 10}

Figura 2 - Nuvem de palavras

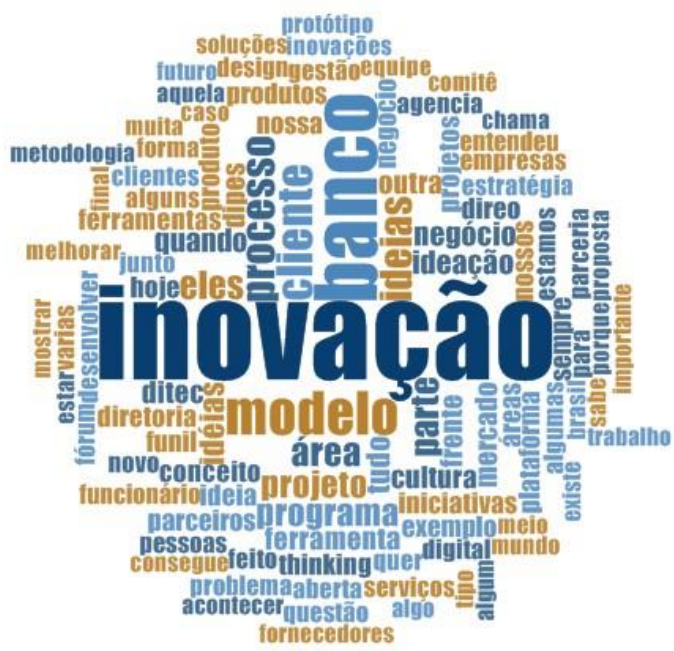

Fonte: elaborada pelos autores com auxílio do software Nvivo versão 10

\section{DISCUSSÃO DOS RESULTADOS}

Evidencia-se a preocupação da instituição financeira em relação à cultura voltada à inovação, a necessidade de alinhamento da inovação à estratégia, a preocupação com a estruturação de uma equipe que a gerencie, a geração de resultado (resultado, que neste caso é a própria inovação), o estabelecimento de métricas para a sua avaliação, e a retroalimentação da estratégia corporativa através dos resultados das inovações. Os resultados obtidos corroboram com estudos realizados por Bruno-Faria e Fonseca (2014) e Tidd, Bessant e Pavitt (2008).

Nota-se que o atual modelo de gestão adotado está centrado em processos internos. Não se verifica, no âmbito do Banco, uma preocupação maior com a forma de se "captar" e se processar ideias externas. No fluxo identificado, não foram citadas as fontes de informações externas inerentes ao processo de inovação, nem mesmo a forma com que ocorre o tratamento das ideias (funil de inovação). Nesse contexto e, apoiado em Chesbrough (2012a), constata-se que a instituição se encontra em um estágio intermediário entre inovação aberta e fechada.

Observa-se ainda, que a instituição financeira faz uma espécie de "separação" entre o que ela chama de "modelo interno de gestão da inovação" e as "ferramentas corporativas de inovação". Nas ferramentas de inovação tem se utilizado de inovação aberta para a realização de algumas campanhas de inovação, principalmente utilizando-se do crowdsourcing (EBOLI; DIB, 2010). Mas percebe-se que 
modelo de gestão da inovação é fechado, ou pelo menos, detém muitas características de um modelo fechado, evidenciado principalmente pelo não compartilhamento das informações para fora da instituição. A empresa considera importante captar informações externas, mas considera complicado compartilhá-las, que pode acarretar em perda de informações sigilosas para a concorrência, conforme apontam também Vladi (2013) e Barri et al. (2014).

Atualmente a empresa possui iniciativas que são apoiadas pontualmente, de forma descentralizada. Possui um programa de inovação formalizado, que está sendo revisto através de uma proposta de um novo modelo de inovação que ainda não é oficial. A função da consultoria externa, além de validar, é dar sugestões para melhoria do modelo. De acordo com o E1, "o que a gente não tem é um programa virtuoso, que a gente está propondo agora, para potencializar estas inovações".

Analisando-se os relatos do E3, confirma-se a estratégia de inovação que está sendo reformulada, envolvendo a participação das principais áreas, entre elas a de estratégia, a de tecnologia e de gestão de pessoas. Ainda segundo o E3, a Diretoria de Tecnologia possui uma área que se dedica "exclusivamente ao processo de inovação, diferente de outras diretorias que ainda não tem esse núcleo. Nós, talvez, sejamos umas das diretorias que esteja mais avançada em termos de processo". Os principais motivos para que a cultura de inovação esteja mais bem disseminada nesta área, é que diversos programas foram testados antes nesta diretoria, pela ideia de que, como ela trabalha com tecnologia, teria um terreno mais fértil para o programa prosperar.

De modo geral, verifica-se que a inovação aberta está presente, porém ela não está sistematizada em todos os seus elementos preconizados pela literatura, conforme Chesbrough (2003, 2006, 2007, 2011, 2012a, 2012b), Doz et al., (2004), Ferro (2010), Herzog e Leker (2011), Howe (2006) e Von Hippel (2005), com destaque para a utilização das fontes de informação e de participação de outros stakeholders, como clientes e colaboradores.

Quando indagados sobre o modelo de gestão adotado, percebe-se que existe uma sinergia de ações entre as diretorias e que os relatos dos entrevistados da diretoria de estratégia e organização (E1 e E2), condizem com as falas dos entrevistados da diretoria de tecnologia (E3 e E4), como pode ser observado no relato do E3:

\footnotetext{
Então a gente está participando junto com eles e surgiram algumas propostas, já fizemos um esboço inicial do que seria esse programa de inovação, e a ideia deles é contratar uma consultoria para nos ajudar, não sei como que vai ser feito essa escolha, mas por enquanto a gente relacionou, há um programa de inovação o que ele precisa de ter, quais as ferramentas que deseja, quais etapas do processo, como que, é preciso de um comitê, são elementos do processo de inovação e ferramentas que a gente se concentrou nesse esboço, e à partir da ai, via vir uma consultoria possivelmente o banco vai contratar para nos ajudar a terminar a implantação desse programa (ENTREVISTADO E3).
}

Percebe-se que os principais desafios da instituição em relação ao processo de inovação, na opinião do E3 e E4, são: como que ocorre a seleção das ideias; quem deve selecionar; quem deve tomar as decisões em questões chaves do processo de inovação. Não se tem ainda um caminho ideal para este processo, se é através de um Workshop, ou um comitê de inovação. Existe uma enorme dificuldade na seleção de ideias e projetos de inovação. Talvez a inovação aberta traga respostas a estas questões, ao permitir o desenvolvimento e discussão de ideias em conjunto com atores externos. Mas para isso, mais uma vez, a instituição financeira se depara com questões envolvendo "informações sigilosas ou estratégicas" típicas da inovação fechada.

Empresas modernas estão desenvolvendo meios de intermediação financeira muito eficiente e de forma aberta, como o Google, Paypal e Bcash (BARRI et al., 2014). O Bcash, por exemplo, é uma 
empresa do grupo Buscapé, que disponibilizou, de forma aberta, a grande base de dados de produtos, ofertas e serviços para desenvolvedores externos à empresa. Por um lado, a iniciativa de inovação aberta aumentou a capacidade da empresa de fornecer aplicações novas, pois a empresa nunca conseguiria manter ou pagar tantos desenvolvedores. Se as aplicações geradas são capazes de gerar receita, elas são divididas entre o Buscapé e o desenvolvedor.

A visão sobre o modelo de gestão da inovação adotado pela instituição financeira, na opinião do E5 e E6, que fazem parte do varejo (unidades táticas e operacionais), é de que o modelo atual, moderno e adequado ao sistema financeiro. Percebe-se que os entrevistados dessas unidades, conforme seus relatos, não tem um conhecimento estratégico do que ocorre na instituição em termos de inovação. Inclusive, foi apontado por eles como possível ponto de melhoria, a maior participação dos funcionários da rede de agências na construção das inovações. Apesar do foco da inovação aberta ser o ambiente externo, é essencial a criação de mecanismos eficientes de comunicação interna, a fim de facilitar o fluxo de informações, observados por Fasnacht (2009) e Chesbrough (2012a).

Analisando as principais tipologias de inovações presentes, assim como os esforços de inovação e as ferramentas utilizadas, através dos relatos dos entrevistados, percebe-se que a instituição financeira até utiliza alguns elementos da inovação aberta. Porém, observa-se diversos aspectos que a caracterizam como inovação fechada. Desta forma este tipo de indústria pode ser classificado como "em transição entre os dois paradigmas" (CHESBROUGH, 2012a).

\section{CONSIDERAÇÕES FINAIS}

O objetivo central do estudo consistiu em analisar o modelo de gestão da inovação de uma instituição financeira brasileira. A partir da análise da instituição financeira, e do seu ambiente, acreditase que o estudo possa contribuir para a aplicação do conhecimento a respeito da inovação aberta, sobretudo em no âmbito das instituições financeiras brasileiras.

Verificou-se que a instituição financeira pratica a inovação aberta em algumas ações pontuais, porém não existe um modelo de gestão da inovação que contemple a inovação aberta, nos aspectos preconizados pela literatura pesquisada. A organização possui ainda muitos elementos, que a caracterizam como de inovação fechada. Dentre eles, a estrutura organizacional hierárquica e centralizada, um baixo incentivo à disseminação da cultura da inovação e baixa exploração de fontes de informações internas e externas. É neste aspecto que o residiu o foco do presente trabalho, ao chamar atenção para um aspecto mais simples, mas talvez um dos mais importantes no processo de inovação aberta: as fontes de informação e o processo de seleção e tratamento das ideias.

O estudo também chama a atenção para a necessidade das instituições financeiras, de forma geral, utilizarem fontes internas e externas no processo de inovação. Verifica-se que na maioria das iniciativas ocorre a absorção de ideias de "fora para dentro", principalmente oriunda da interação com clientes, porém, a inovação aberta exige também que o fluxo de ideias ocorra de "dentro para fora". Existem ações envolvendo o uso de informações internas, através de campanhas com os colaboradores, mas acontecem de forma dispersa, envolvendo algumas áreas específicas do Banco, como a área de tecnologia, por exemplo. Sugere-se que deva haver uma maior interação com a rede de agências, que são o elo principal de ligação entre a empresa e o cliente.

As principais dificuldades observadas no processo de inovação, na instituição financeira analisada, estão relacionadas à estrutura organizacional atual e à legislação que a ela se aplica, por ser atrelada ao governo federal. Pode-se concluir com o estudo, que a organização está em um estágio intermediário, que integra ora características da inovação fechada e ora da inovação aberta. 
Em relação às limitações inerentes aos estudos de caso (YIN, 2005), cabe destacar que o presente estudo envolveu apenas uma instituição financeira. Para estudos futuros, sugere-se ainda testar as categorias propostas, visando sua validação, críticas e estudo nas demais organizações financeiras. Da mesma forma, não é possível afirmar que a inovação aberta é de fato a melhor solução para a melhoria da competitividade em instituições financeiras brasileiras.

\section{REFERÊNCIAS}

BANCO CENTRAL DO BRASIL. Política Monetária e Operações de Crédito do Sistema Financeiro. Disponível em: <http://www.bcb.gov.br/?ECOIMPOM>. Acesso em: 08 jun. 2014.

BARBIERI, J. C.; SIMANTOB, M. A. (Org.). Organizações Inovadoras do Setor Financeiro: Teoria e Casos de Sucesso. São Paulo: Saraiva, 2009.

BARDIN, L. Análise de Conteúdo. Lisboa, Portugal: Edições 70, LDA, 2009.

BARRI, I. et al. Open Innovation in the Financial Services Sector: why and how to take action. GFT, 2014. Disponível em:

$<\mathrm{http} / / /$ www.gft.com/index/services/perspectives/blue_paper_open_innovation_in_financial_services. html>. Acesso em: 28 fev. 2015.

BRUNO-FARIA, M. F.; FONSECA, M. V. A. Cultura de Inovação: Conceitos e Modelos Teóricos. RAC-Revista de Administração Contemporânea, v. 18, n. 4, p. 372-396, 2014.

CERNEV, A. K.; DINIZ, E. H.; JAYO, M. As cinco ondas de inovações tecnológicas em bancos. In: BARBIERI, J. C.; SIMANTOB, M. A (Org.). Organizações Inovadoras do Setor Financeiro: Teoria e Casos de Sucesso. São Paulo: Saraiva, 2009.

CHESBROUGH, H. The era of open innovation. MIT Sloan Management Review, v. 44, n. 3, p. 35, 2003.

CHESBROUGH, H.; VANHAVERBEKE, W.; WEST, J. (Ed.). Open innovation: Researching a new paradigm. Oxford university press, 2006.

CHESBROUGH, H.; APPLEYARD, M.; M. Open innovation and strategy. California management review, v. 50, n. 1, p. 57, 2007.

CHESBROUGH, H. Why companies should have open business models. MIT Sloan management review, v. 48, n. 2, 2007.

CHESBROUGH, H. Open services innovation: rethinking your business to grow and compete in a new era. John Wiley\& Sons, 2011.

CHESBROUGH, H. Inovação Aberta: como criar e lucrar com a tecnologia. Tradução: Luiz Claudio de Queiroz Faria. Porto Alegre: Bookman, 2012a.

CHESBROUGH, H. Open innovation: where weve been and where were going. ResearchTechnology Management, v. 55, n. 4, p. 20-27, 2012b.

DIEHL, R. J.; RUFFONI, J. O Paradigma da Inovação Aberta: dois estudos de caso de empresas do Rio Grande do Sul. Perspectiva Econômica, v. 8, n. 1, 2012.

DOZ, Y.; SANTOS, J.; WILLIAMSON, P. Is your innovation process global? MIT Sloan

Management Review, v. 45, n. 4, p. 31-37, 2004. 
EBOLI, L. R.; DIB, L. A. Criação coletiva na web 2.0: um Estudo de Caso em uma Empresa Brasileira de Crowdsourcing. Encontro da Associação Nacional de Pós-Graduação e Pesquisa em Administração, v. 35, 2010.

ENGENHOFF, R.; BALESTRIN, A. Inovação fechada versus inovação aberta: um estudo de caso da indústria de cutelaria. XXV Simpósio de Gestão da inovação tecnológica. Brasília, DF - 22 a 24 de Outubro de 2008.

FASNACHT, D. Open Innovation in the Financial Services: Growing Through Opennes, Flexibility and Costumer Integration, Berlin, 2009.

FACÓ, J. F. B.; SIMANTOB, M. A. Inovação na indústria financeira. In: BARBIERI, José Carlos; SIMANTOB, Moysés Alberto (Org.). Organizações Inovadoras do Setor Financeiro: Teoria e Casos de Sucesso. São Paulo: Saraiva, 2009.

FERRO, A. F. P. Gestão da inovação aberta: práticas e competências em P\&D Colaborativa. 2010. Tese de Doutorado. Tese (Doutorado em Política Científica e Tecnológica). Universidade Estadual de Campinas, Campinas, 2010.

HERZOG, P.; LEKER, J. Open and closed innovation: different cultures for different strategies. Springer, 2011.

HOWE, J. The rise of crowdsourcing. Wired magazine, v. 14, n. 6, p. 1-4, 2006.

LINDEGAARD, S. A revolução da inovação aberta. Editora Évora, 2011.

OCDE; EUROSTAT. Manual de Oslo: diretrizes para coleta e interpretação de dados sobre inovação. $3^{\mathrm{a}}$ edição. FINEP, 2005.

PIATTO, E. B.; BERNARDES, R.; MORAES, E. Open Capabilities: Estudo de Caso sobre a Gestão de Competências para Inovação Aberta na Natura. XXXIV Encontro da ANPAD. Rio de Janeiro/RJ 25 a 29 de setembro de 2010.

PINHEIRO, T.; ALT, L.; PONTES, F. Design Thinking Brasil: empatia, colaboração e experimentação para pessoas, negócios e sociedade. Rio de Janeiro, RJ. Elsevier, 2011.

PIRES, M. G.; MARCONDES, Reynaldo Cavalheiro. Conhecimento, inovação e competência em organizações financeiras: uma análise sob o ponto de vista de gestores de bancos. RAC, Edição Especial, p. 61-78, 2004.

PIRES, A. M. B.; TEIXEIRA, F. L .C; HASTENREITER FILHO, H. N. Colaboração nas atividades de pesquisa desenvolvimento e inovação: o que nos ensina o Modelo de Centros e Redes de Excelência Petrobras/COPPE UFRJ.Organizações \& Sociedade, v. 19, n. 62, p. 507-526, 2012.

PRAHALAD, C. K.; RAMASWAMY, V. The new frontier of experience innovation. MIT Sloan Management Review, v. 44, n. 4, p. 12, 2003.

SCHUMPETER, J. A. Teoria do desenvolvimento econômico: uma investigação sobre lucros, capital, crédito, juro e o ciclo econômico. Tradução Maria Sílvia Possas. São Paulo: Nova cultural, 1997. (Obra original publicada em 1934).

SILVA, E. N.; PORTO JÚNIOR, S.S. Sistema financeiro e crescimento econômico: uma aplicação de regressão quantílica. Economia Aplicada, v. 10, n. 3, p. 425-442, 2006.

TIDD, J.; BESSANT, J.; PAVITT, K. Gestão da inovação. Bookman, 2008.

TIGRE, P. Gestão da inovação: a economia da tecnologia no Brasil. Elsevier Brasil, 2006. 
VAN DER MEER, H. Open innovation-the Dutch treat: challenges in thinking in business models. Creativity and Innovation Management, v. 16, n. 2, p. 192-202, 2007.

VON HIPPEL, E. Democratizing innovation. MIT press, 2005.

VLADI, B. The open innovation model: explaining the factors that hinder its implementation in the albanian banking system. In: CBU International Conference Proceedings. p. 69-74. 2013.

YIN, R. Estudo de caso: planejamento e métodos. 3. ed. Porto Alegre: Bookman, 2005. 